\title{
A muscular bridge with an absent left main trunk: A rare coronary artery anomaly
}

Hamit Serdar Başbuğ, Yalçın Günerhan, Hakan Göçer, Kanat Özışık

Department of Cardiovascular Surgery, Medical Faculty of Kafkas University, Kars, Turkey

Received: November 19, 2016 Accepted: December 07, 2016 Published online: April 17, 2017

The appearance, prevalence, and the clinical importance of the coronary artery anomalies should be well-appreciated by the cardiologists and the cardiovascular surgeons who are engaged with the coronary artery disease. ${ }^{[1]}$ Coronary artery anomalies are seen approximately $6 \%$ of the general population. ${ }^{[2]}$

An 84-year-old male was admitted to the emergency department with a complaint of angina pectoris. His vital signs were normal, including the blood pressure $(130 / 65 \mathrm{mmHg})$ and the heart
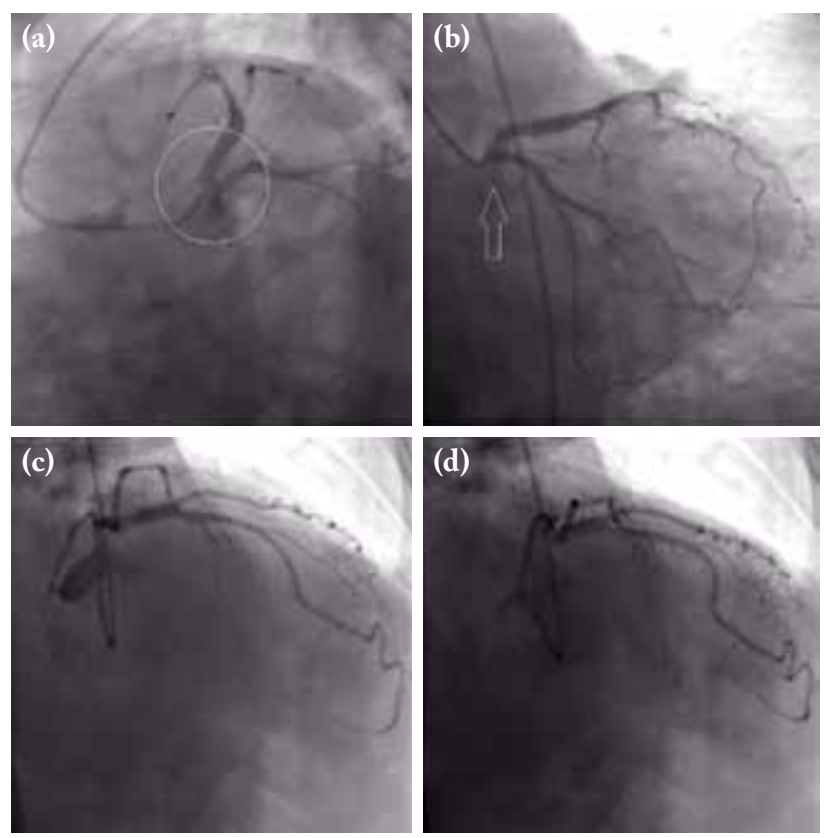

Figure 1. (a) A left anterior oblique view showing the absence of the left main trunk. (b) Arrow indicates the separate origins of the left anterior descending and the circumflex artery. (c) Left anterior descending artery in diastole. (d) Left anterior descending artery in systole (Arrow indicates the muscular bridge). rate $(59 \mathrm{bpm})$. Although his troponin-I levels were within normal limits, coronary angiography was performed to exclude possible underestimation of a coronary artery disease. Although no prominent lesion in the coronary vasculature was detected, a rare anatomic variation was observed. The left coronary arteries were originating from the aorta with a separate ostium having no common left main trunk (Figure 1a, b). The course of the left coronary arteries was normal. However, there was a muscular bridge on the mid-portion of left anterior descending artery (Figure 1c, d). The origin and course of the right coronary artery were normal.

We present this case with an uncommon anatomical variation to highlight the variability of the normally functioning vascular structures. The coronary artery anomalies in which the origin is from wrong coronary sinus may have a risk of sudden death in the younger population. ${ }^{[3]}$ Therefore, this significantly and clinically important condition should be kept in mind, in cases of a coronary artery anomaly.

\section{Declaration of conflicting interests}

The authors declared no conflicts of interest with respect to the authorship and/or publication of this article.

\section{Funding}

The authors received no financial support for the research and/or authorship of this article.

\section{REFERENCES}

1. Angelini P. Coronary artery anomalies: an entity in search of an identity. Circulation 2007;115:1296-305.

Corresponding author: Hamit Serdar Başbuğ, MD. Kafkas Üniversitesi Tıp Fakültesi Kalp ve Damar Cerrahisi Anabilim Dal, 36100 Kars, Turkey.

Tel: +90 474 - 2251190 e-mail: s_basbug@hotmail.com 
2. Earls JP. Coronary artery anomalies. Tech Vasc Interv Radiol 2006;9:210-7.

3. Basso C, Maron BJ, Corrado D, Thiene G. Clinical profile of congenital coronary artery anomalies with origin from the wrong aortic sinus leading to sudden death in young competitive athletes. J Am Coll Cardiol 2000;35:1493-501. 